\title{
Resonance Frequency Detection Technique in Grid- connected Inverter Systems Based on Double-order Digitalized Filter
}

\author{
Hamza Khalfalla ${ }^{1,2}$, Salaheddine Ethni ${ }^{1}$, Nasiru B. Kadandani ${ }^{1,3}$ and Volker Pickert ${ }^{1}$ \\ ${ }^{1}$ School of Engineering, Newcastle University, ${ }^{2}$ The General Electricity Company of Libya (GECOL) \\ ${ }^{3}$ Department of Electrical Engineering, Bayero University, Kano, Nigeria \\ Newcastle Upon Tyne, NE1 7RU, United Kingdom \\ Hamza.khalfalla@ncl.ac.uk, Salaheddine.ethni@ncl.ac.uk, nbkadandani.ele@buk.edu.ng
}

\begin{abstract}
Voltage source inverters (VSI) employed in distribution generation systems are usually interfaced to the grid via a low-pass LCL filter. This filter has a resonance frequency peak which can vary with respect to grid impedance, leading to instability issues if not properly suppressed. This paper proposes a resonance detection method based on a double-order digital band-pass filter. The digital filter extracts only the harmonic components around the resonance frequency from the injected grid current waveform while attenuating other frequencies outside its passband. The range of resonance frequencies has been determined by a grid impedance estimation technique. The detection method has been implemented in an experimental singlephase grid-connected inverter system and the practical results validate the effectiveness of the proposed method.
\end{abstract}

Keywords-Resonance Frequency, Digital Bandpass filter, Resonance Detection, Grid Connected Inverter

\section{INTRODUCTION}

Demand for renewable energy systems such as wind and PV systems has shown significant growth in recent years, driven by the increasing efficiency and reductions in the cost of PV modules. Today, distribution generation-based PV systems make a major contribution to total global electricity production. It has been reported that PV capacity in 2016 had increased by a factor of $43.14 \%$ from just $7.0 \mathrm{GW}$ in 2006 to a new record figure of $303 \mathrm{GW}$ worldwide [1]. However, the power produced from distributed generation systems such as PV panels is in the form of DC voltage, which necessitates the use of a pulse-width modulation (PWM) inverter for conversion into AC components and hence connected to the utility network[2]. To comply with grid codes, passive filters are required to interface the voltage source inverter (VSI) with the grid in order to attenuate the high switching frequencies associated with the PWM from being injected into the grid. LCL filters are generally used in gridconnected inverter systems due to their advantages over other types such as L and LC filters in terms of harmonic attenuation and cost savings [3]. However, the LCL filter is a third-order resonant circuit, which has a resonance frequency peak that is determined by the filter components. This resonance frequency has to remain within a range between one-half of the switching frequency and ten times the fundamental frequency to give smooth operation and avoid resonance problems in the lower and higher parts of the frequency spectrum [4]. However, undesired resonance effects can still occur which may lead to instability problems, especially in weak grid systems in which a wide range of grid impedance variations are expected [5]. Consequently, the fixed resonance frequency assumed in the design process of the LCL filter is no longer fixed anymore but changes whenever the equivalent grid impedance changes. In addition to instability problems, the existence of the resonance frequency can weaken the power quality and damage protection devices [6]. Therefore, appropriate damping techniques must be added to the system in order to suppress or even prevent the resonance effects of the LCL filter. In fact, there are other sources of resonance in the network besides that of the local filter, such as parallel resonance with other inverters connected to the same point of common coupling (PCC) and series resonance with the grid. In the literature, the two widely reported damping methods are passive and active damping. The passive solution can be achieved by adding a resistor in series with the filter capacitor without compromising the filter's effectiveness [7-9]. Although this technique is simple and reliable it can lead to additional power losses which are undesirable especially in high power applications. Alternatively, active damping techniques which integrated into the control function are adopted as they do not cause additional power dissipation and meanwhile provide flexible resonance frequency suppression [10-12]. However, active methods are sensitive to parameter uncertainties and their controllability is limited by the sampling frequency of the adopted controller [13]. Combinations of passive and active damping techniques have also been proposed, such as hybrid damping and adaptive cascaded notch filters to ensure operational stability [14]. In summary, the detection and attenuation of the resonance frequency are features required in 
grid-connected inverter systems in order to guarantee system stability. From this perspective, this paper proposes a simple method for resonance detection that can be used to suppress resonance or predict changes in system parameters such as grid impedance. The proposed scheme employs a second-order digital band-pass filter to extract only the harmonic components around the resonance frequency from the injected current waveform. During practical experiments, the range of resonance frequency has been defined by controllably exciting the resonance frequency. The paper is organized as follows. Section II presents description of the system along with the proposed method. In section III, the resonance mechanism in gridconnected inverter systems is addressed and introduce the principle. Measured results and conclusions are then presented in sections IV and V respectively.

\section{PROPOSED METHOD}

\section{A. System Discribtion.}

The system consists of a DC power supply (LP600-4 0-600V 0-4A) which is connected to a silicon carbide Mosfet H-bridge inverter. The inverter output is connected to a low-pass LCL filter in series with a tapped inductor which represents the variation in grid inductance. Via the LCL filter, the inverter is coupled to the distribution network via an isolation transformer and a variac for safety and protection purposes, and to step down the AC mains voltage of $230 \mathrm{~V}$. The emulated grid impedance is inserted between the LCL filter and the variac, while the current and voltage sensors are placed before this impedance. In this case the grid impedance is seen as part of the grid. A digital Yokogawa WT310 power meter is used to monitor and analyze the output waveforms of the system. The system is provided with a protection circuit that controls the on and off switching process which can quickly disconnect the system in case of emergency. Fig.1 shows a photograph of the experimental system along with its protection unit, while the system specifications and parameters used in the practical work are given in tables I and II respectively.

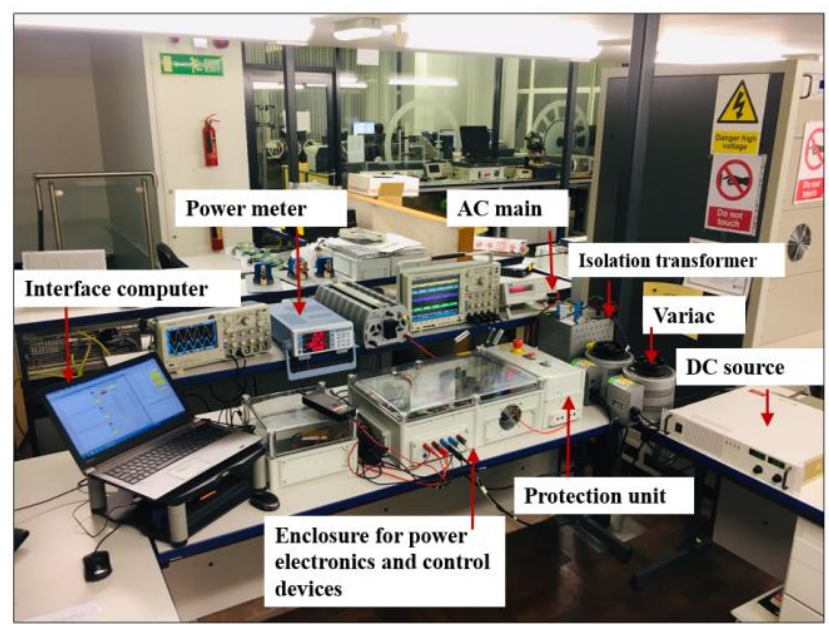

Fig. 1. Resonance frequency variation as function of grid inductance.
The control function of the VSI in this research is implemented by a floating-point digital DSP TM320F28337 from Texas Instruments. The injected grid current is controlled by a proportional resonance (PR) controller which introduce infinit gain at the selected frequency leadint to the elimination of steady-state error [15].

TABLE I. CONVERTER SPECIFICATIONS

\begin{tabular}{ccc}
\hline Symbol & Parameter & Value \\
\hline $\mathbf{P}_{\mathbf{0}}$ & Output Power & $200 \mathrm{~W}$ \\
$\mathbf{V}_{\mathbf{D C}}$ & DC-Link Voltage & $100 \mathrm{VDC}$ \\
$\mathbf{V g}$ & Grid Voltage & $45 \mathrm{VAC}$ \\
$\boldsymbol{f}_{\mathbf{s w}}$ & Switching Frequency & $20 \mathrm{kHz}$ \\
\hline
\end{tabular}

TABLE II. CONVERTER PARAMETERS

\begin{tabular}{ccc}
\hline Symbol & Parameter & Value \\
\hline $\mathbf{L}_{1}$ & Inverter Side Inductor & $0.6 \mathrm{mH}$ \\
$\mathbf{L}_{2}$ & Grid Side Inductor & $0.2 \mathrm{mH}$ \\
$\mathbf{C}_{f}$ & Filter Capacitor & $10 \mu \mathrm{F}$ \\
$\mathbf{L}_{\mathbf{g}}$ & Grid inductance & $0.1-0.8 \mathrm{mH}$ \\
\hline
\end{tabular}

B. Resonance Mechanism in grid-connected inverter systems.

The phenomenon of resonance is observed in an electrical circuit when the capacitor reactance is equal to that of inductive reactance. In this case, large quantities of exchanging energy oscillates between the two reactance. Eventually, the response of the system will be significantly different from that of other frequencies and thus stability performance will be affected. In grid-connected inverter systems, resonance can be excited when the change in grid impedance shifts the resonance frequency of the whole system. In turn, this will interact with the filter impedance and the switching frequency of the VSI, leading to distortions in the current and voltage signals. It is worth mentioning that the reasons behind possible variations in interfacing impedance seen by the inverter can include cable overload, saturation and temperature effects and loading conditions [16]. According to IEC60725 standards [17], the reference impedance of single-phase, two-wire connection, 50 $\mathrm{Hz}$ in the United Kindom can vary up to $0.796 \mathrm{mH}$. Therefore, the practical system is interfaced to the grid with different values of inductance in the range of $0.2 \mathrm{mH}$ to $0.8 \mathrm{mH}$. The influence of variation in grid inductance on the range of resonance frequency is determined by the formula given in Eq.1, which shows that the position of the resonance frequency changes according to changes in grid inductance.

$$
\omega_{\text {res }}=\sqrt{\frac{L_{1}+L_{2}+L_{g}}{C_{f} L_{1}\left(L_{2}+L_{g}\right)}} \quad \mathrm{rad} / \mathrm{second}
$$

where $L g$ represents grid inductance and $L_{l}, L_{2}$ and $C_{f}$ are the passive components of the LCL filter. To evaluate the impact 
that variation in grid inductance has on the system resonance frequency, a Bode diagram of the filter's transfer function has been generated in MatLab as given in Fig.2.

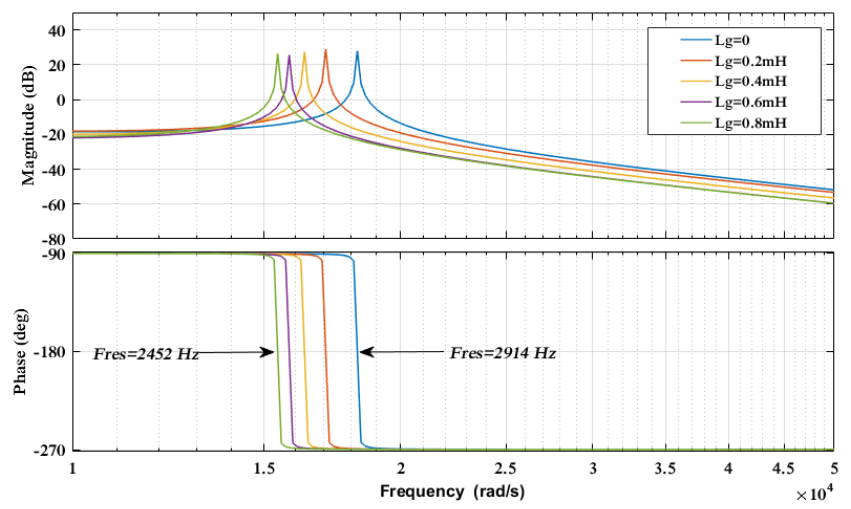

Fig. 2. Variation in resonance frequency with variation in interfacing grid inductance.

It is also obvious from the figure that the resonant frequency is reduced significantly due to the increase in grid impedance. For instance, in a typical stiff condition $(\mathrm{Lg}=0 \mathrm{mH})$, the resonance frequency was as high as $2914 \mathrm{~Hz}$, while in the case of weak grid conditions the presence of high value of grid inductance $(0.8 \mathrm{mH})$ has clearly shifted the resonance frequency toward the low frequency range at $2452 \mathrm{~Hz}$. In fact, this resonance can be even lower in networks with high penetration of grid-connected inverter connected in parallel at the same point of common coupling (PCC). In this case the dynamic and stability problems might rise in both low and high frequency ranges. The relationship between system stability and resonance frequency has been detailed in [18].

\section{Proposed Method of resonance detection.}

The range of resonance frequency is determined by the range of grid impedance variation and the components of the LCL filter. The method proposed in this paper relies on extracting only the harmonic components around the resonance frequency from the injected current waveform. To accomplish this, a second-order digital band-pass filter is implemented within the control function of the VSI as depicted in Fig.3, which also shows the discrete transfer function of the filter.

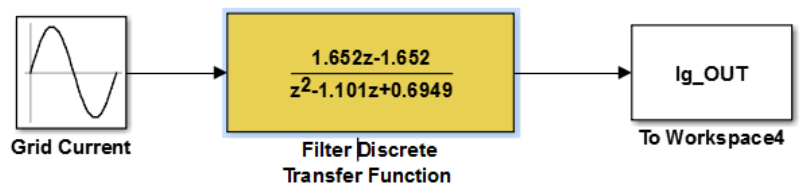

Fig. 3. Block diagram of the digital band-pass filter.
The digital filter is designed in such a way so that only certain frequencies pass through it in a very selective way. The high gain of the digital filter can magnify the harmonic magnitudes for ease of detection even if the LCL filter is hardly resonating. However, the bandwidth of the digital filter has to be firstly specified in order to be effectively implemented in practice. This has been achieved by controllably exciting the resonance of the LCL filter by increasing the proportional gain of the PR controller as reported in another study [19]. In this way, the system is pushed out of the stability region and thus the magnitude of the harmonic components around the resonance frequency will be considerably magnified. During the experimental work, the VSI has been interfaced to the gird via an emulated grid inductance of $0.3 \mathrm{mH}$ and $0.8 \mathrm{mH}$ and the peak of the resulting resonance is then recorded using fast Fourier transform FFT analysis.

\section{EXPERIMENTAL RESULTS}

A schematic diagram of the experimental system is shown in Fig.4, in which a digital band-pass filter is implemented. Fig.5 shows experimental results for three waveforms: the voltage waveform at the PCC $\left(V_{P C C}\right)$, the grid current waveforms $\left(I_{g}\right)$, and the output voltage waveform from the inverter $\left(V_{\text {in }}\right)$. These waveforms represent the operational performance of the experimental single-phase grid-connected inverter. It can also be noticed that the system is working at unity power factor since the grid current is in phase with respect to the grid voltage.

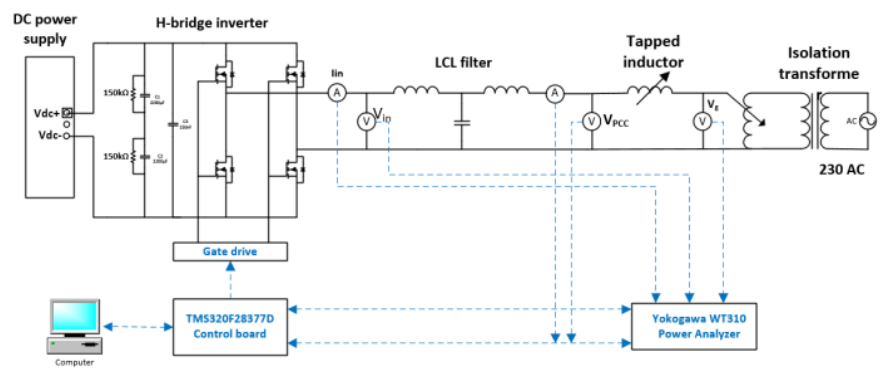

Fig. 4. Schematic diagram of the experimental grid-connected inverter system.

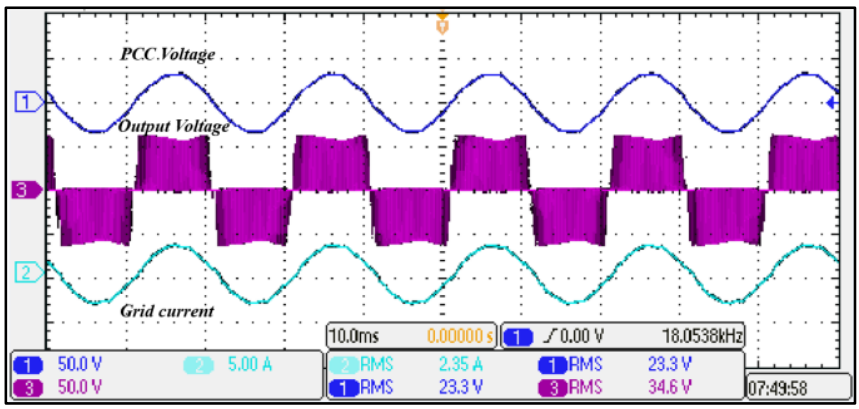

Fig. 5. System operation with PR controller. 
Based on the fact that the resonance frequency changes whenever the grid inductance changes, and that the considered variation in grid inductance is in the range between $0.1 \mathrm{mH}$ to $0.8 \mathrm{mH}$, thus a practical experiment has been carried out for two values of grid inductance of $0.1 \mathrm{mH}$, and $0.8 \mathrm{mH}$ in order to determine the exact bandwidth of the required band-pass filter. It is possible to excite the resonance of the LCL filter by slightly increasing the proportional gain of the current controller to the point where the closed-loop reaches the limits of the stability region.

During the practical experiment, the controller's proportional gain has been carefully increased by steps of $10 \%$ up to the value at which the system become unstable. The operation of instability was maintained for 0.2 second in order to ensure that the resolution required for the FFT analysis was achieved. Fig.6 shows the experimental results of resonance excitation near the limit of the stability region and beyond its limit.

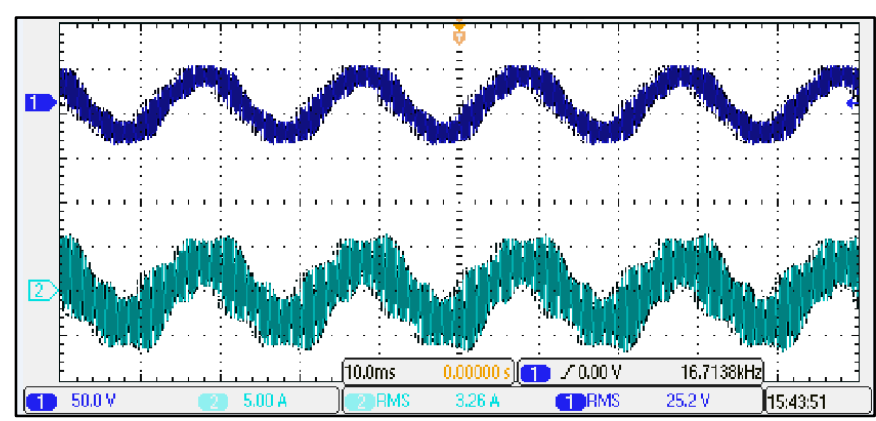

(a)

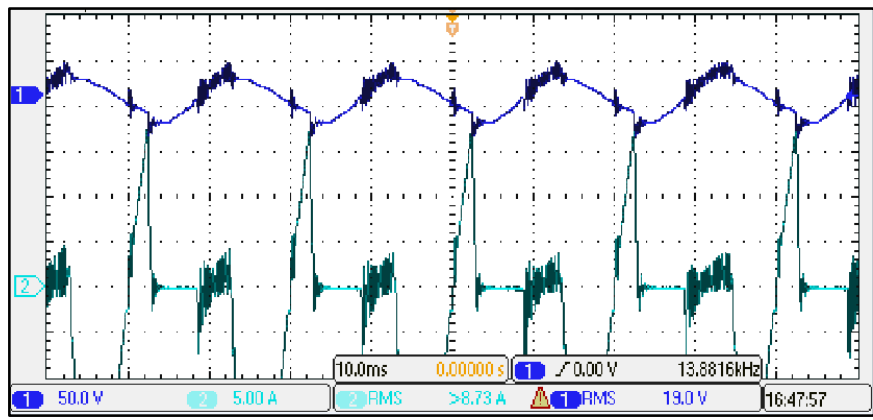

(b)

Fig.6 Resonance excitation of the system: (a) near the limit of the region of stability, (b) beyond the limit of the region of stability

By carrying out an FFT analysis of the highly distorted signal of the grid current for both cases, the range of resonance frequency was experimentally determined. The harmonic performance of the measured grid current in the case of values of $\mathrm{Lg}$ equal to $0.1 \mathrm{mH}$ and $0.8 \mathrm{mH}$ are shown in Fig.7. As can be seen from the figure, the resonance frequency is equal to $2600 \mathrm{~Hz}$ in the case of $0.1 \mathrm{mH}$, while with $0.8 \mathrm{mH}$ of grid inductance the resonance frequency is equal to $2150 \mathrm{~Hz}$. In accordance with this range, the parameters of the digital filter have been selected as given in Table III.

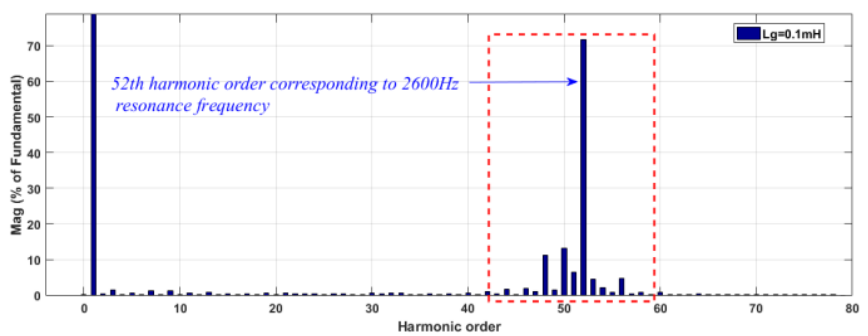

(a)

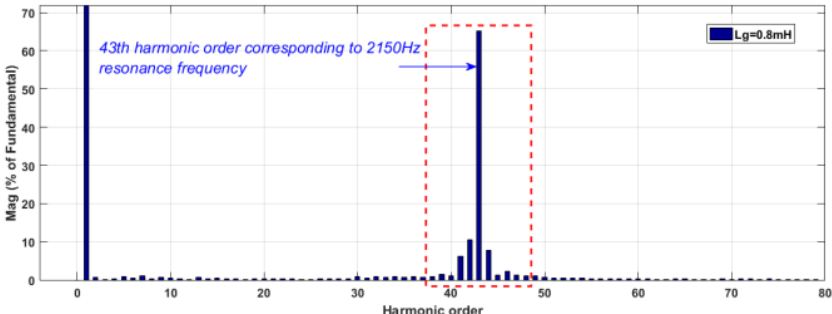

(b)

Fig.7 Harmonic performance of measured grid current, (a) $0.1 \mathrm{mH}$ and (b) $0.8 \mathrm{mH}$

TABLEIII. SPECIFICATIONS OF BAND-PASS FILTER

\begin{tabular}{ccc}
\hline Symbol & Parameter & Value \\
\hline $\mathbf{n}$ & Order & 2 \\
$\mathbf{A g}$ & Passband Gain & $25 \mathrm{~dB}$ \\
$\mathbf{f}$ & Centre Frequency & $2.2 \mathrm{kHz}$ \\
$\boldsymbol{B} \boldsymbol{W}$ & Bandwidth & $1 \mathrm{kHz}$ \\
\hline
\end{tabular}

In the practical experiment, the sensed current waveform is transmitted from the microprocessor to the Matlab workspace through the general user interface (GUI). Once these data are available in the Matlab workspace, FFT analysis of the output signal of the digital band-pass filter is conducted. The performance of the designed band-pass filter has been assessed in terms of the filtering effect and resonance detection at different values of grid inductance. Fig.8 and 9 show the performance of the digital filter and the FFT analysis to the output signals at $0.3 \mathrm{mH}$ and $0.8 \mathrm{mH}$ of grid inductance respectively.

As it can be seen from both figures, the designed digital band-pass filter was able to filter out the harmonic components in the form of an oscillation signal within the selected pass-band of the digital filter, which in the range of 30th and 59th harmonics as shown in Figs 8.(a) and 9.(a). Although the output current signals from the digital filter under both cases of grid inductance have similar shapes, however, the FFT analysis to the filter output signal in both cases shows a significant 
difference, for instance, the level of THD in the filter output signal with $0.8 \mathrm{mH}$ was almost four times higher than that in the case of $0.3 \mathrm{mH}$ of grid inductance, this can be clearly noticed from Figs 8. (b) and 9. (b). these finding results confirm that the higher the grid inductance the more distortion presents in the grid current. In addition, the finding results confirm that the designed digital band-pass filter has magnified the magnitudes of the harmonic components within the selected bandwidth due to the high pass-band gain.

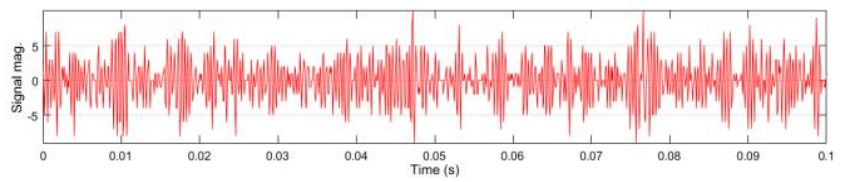

(a)

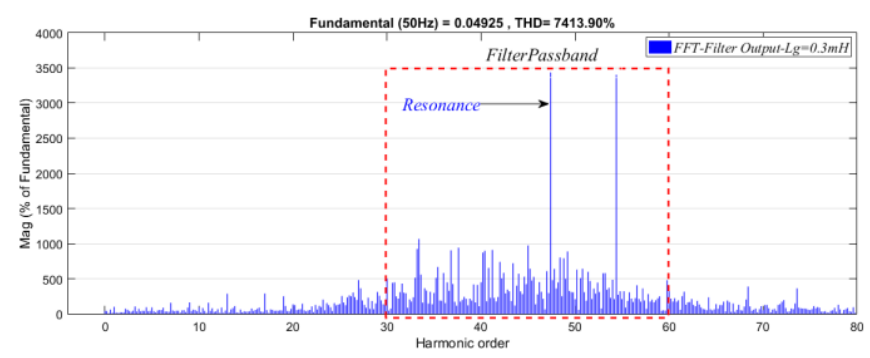

(b)

Fig.8 Digital filter operation, (a) Output current signal from the digital bandpass filter, (b) FFT analysis of the output current signal from the digital bandpass filter at $0.3 \mathrm{mH}$ of grid inductance

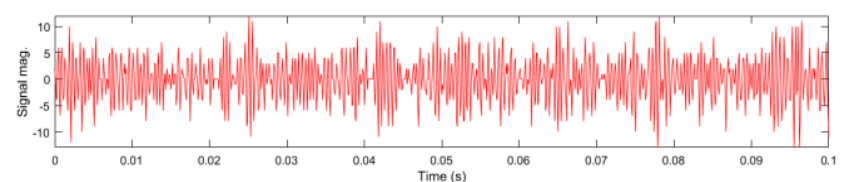

(a)

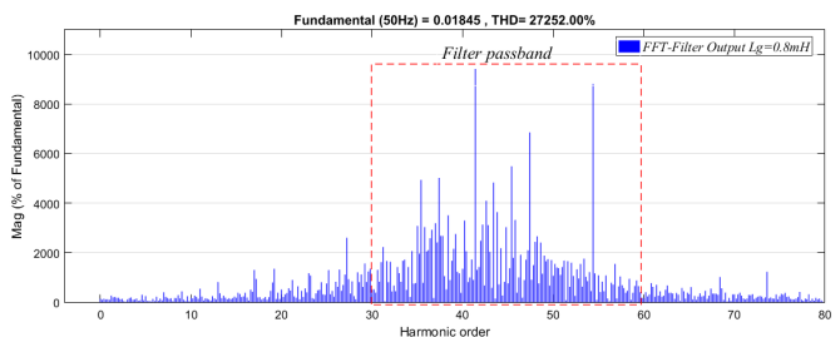

(b)

Fig.9 Digital filter operation, (a) Output current signal from the digital bandpass filter, (b) FFT analysis of the output current signal from the digital bandpass filter at $0.8 \mathrm{mH}$ of grid inductance

\section{CONCLUSION}

In this paper, a resonance detection method is presented. A digital band-pass filter is implemented within the control function of a single-phase grid-connected inverter system. The design of the filter is based on determining the range of resonance frequency of the system. This has been achieved by carefully exciting the resonance in the system, particularly by increasing the controller gain. Experimental results of singlephase grid-connected inverter system demonstrate the principle. The determination of resonance frequency range can be used in other applications such as islanding detection and grid impedance estimation.

\section{REFERENCES}

[1]
J. Liu, L. Zhou, B. Li, C. Zheng, and B. Xie, "Modeling and Analysis of a Digitally Controlled Grid-Connected Large-Scale Centralized PV System," IEEE Transactions on Power Electronics, vol. 33, pp. 4000-4014, 2018.

M. Muhammad, M. Armstrong, and M. A. Elgendy, "Modelling and control of non-isolated high voltage gain boost converter employing coupled inductor and switched capacitor," in 2016 International Conference for Students on Applied Engineering (ICSAE), 2016, pp. 312-317.

A. Reznik, M. G. Simões, A. Al-Durra, and S. M. Muyeen, "Filter Design and Performance Analysis for Grid-Interconnected Systems," IEEE Transactions on Industry Applications, vol. 50, pp. 1225-1232, 2014.

M. Liserre, F. Blaabjerg, and S. Hansen, "Design and control of an LCL-filter-based three-phase active rectifier," IEEE Transactions on Industry Applications, vol. 41, pp. 1281-1291, 2005.

C. Zou, B. Liu, S. Duan, and R. Li, "Influence of Delay on System Stability and Delay Optimization of GridConnected Inverters With LCL Filter," IEEE Transactions on Industrial Informatics, vol. 10, pp. 1775-1784, 2014.

J. Fang, G. Xiao, X. Yang, and Y. Tang, "Parameter Design of a Novel Series-Parallel-Resonant LCLFilter for Single-Phase Half-Bridge Active Power Filters," IEEE Transactions on Power Electronics, vol. 32, pp. 200-217, 2017.

R. Peña-Alzola, M. Liserre, F. Blaabjerg, R. Sebastián, J. Dannehl, and F. W. Fuchs, "Analysis of the Passive Damping Losses in LCL-Filter-Based Grid Converters," IEEE Transactions on Power Electronics, vol. 28, pp. 2642-2646, 2013.

W. Wu, Y. He, T. Tang, and F. Blaabjerg, "A New Design Method for the Passive Damped LCL and LLCL Filter-Based Single-Phase Grid-Tied Inverter," IEEE Transactions on Industrial Electronics, vol. 60, pp. 4339-4350, 2013.

R. N. Beres, X. Wang, M. Liserre, F. Blaabjerg, and C. L. Bak, "A Review of Passive Power Filters for 
Three-Phase Grid-Connected Voltage-Source Converters," IEEE Journal of Emerging and Selected Topics in Power Electronics, vol. 4, pp. 54-69, 2016.

[10] J. C. Giacomini, L. Michels, H. Pinheiro, and C. Rech, "Active Damping Scheme for Leakage Current Reduction in Transformerless Three-Phase GridConnected PV Inverters," IEEE Transactions on Power Electronics, vol. 33, pp. 3988-3999, 2018.

[11] D. Pan, X. Ruan, C. Bao, W. Li, and X. Wang, "Capacitor-Current-Feedback Active Damping With Reduced Computation Delay for Improving Robustness of LCL-Type Grid-Connected Inverter," IEEE Transactions on Power Electronics, vol. 29, pp. 3414-3427, 2014.

[12] W. Wu, Y. Liu, Y. He, H. S. Chung, M. Liserre, and F. Blaabjerg, "Damping Methods for Resonances Caused by LCL-Filter-Based Current-Controlled Grid-Tied Power Inverters: An Overview," IEEE Transactions on Industrial Electronics, vol. 64, pp. 7402-7413, 2017.

[13] J. Dannehl, M. Liserre, and F. W. Fuchs, "Filter-Based Active Damping of Voltage Source Converters With LCL Filter," IEEE Transactions on Industrial Electronics, vol. 58, pp. 3623-3633, 2011.

[14] R. Peña-Alzola, M. Liserre, F. Blaabjerg, M. Ordonez, and T. Kerekes, "A Self-commissioning Notch Filter for Active Damping in a Three-Phase LCL -FilterBased Grid-Tie Converter," IEEE Transactions on Power Electronics, vol. 29, pp. 6754-6761, 2014.
T. Ye, N. Dai, C. Lam, M. Wong, and J. M. Guerrero, "Analysis, Design, and Implementation of a QuasiProportional-Resonant Controller for a Multifunctional Capacitive-Coupling Grid-Connected Inverter," IEEE Transactions on Industry Applications, vol. 52, pp. 4269-4280, 2016.

[16] Y. A. I. Mohamed, "Mitigation of Converter-Grid Resonance, Grid-Induced Distortion, and Parametric Instabilities in Converter-Based Distributed Generation," IEEE Transactions on Power Electronics, vol. 26, pp. 983-996, 2011.

[17] I. Hernando-Gil, H. Shi, F. Li, S. Djokic, and M. Lehtonen, "Evaluation of Fault Levels and Power Supply Network Impedances in 230/400 V $50 \mathrm{~Hz}$ Generic Distribution Systems," IEEE Transactions on Power Delivery, vol. 32, pp. 768-777, 2017.

[18] B. Xie, L. Zhou, C. Zheng, and Q. Zhang, "Stability and resonance analysis and improved design of $\mathrm{N}$ paralleled grid-connected PV inverters coupled due to grid impedance," in 2018 IEEE Applied Power Electronics Conference and Exposition (APEC), 2018, pp. 362-367.

[19] M. Liserre, F. Blaabjerg, and R. Teodorescu, "Grid Impedance Estimation via Excitation of LCL-Filter Resonance," IEEE Transactions on Industry Applications, vol. 43, pp. 1401-1407, 2007. 